\title{
Elementos para uma psicologia no pensamento de Søren Kierkegaard
}

\section{Elements for a Psychology on Søren Kierkegaard's Thought}

\section{Marcos Ricardo J anzen*}

Universidade Federal do Rio Grande do Sul, Porto Alegre, Rio Grande do Sul, Brasil

\section{Adriano Holanda**}

Universidade Federal do Paraná, Curitiba, Paraná, Brasil

\begin{abstract}
RESUMO
Este artigo aborda o existencialismo vivido de Sören Kierkegaard, e aponta algumas questões importantes para uma relação com a psicologia. Iniciando com sua biografia, de vasta importância para o entendimento de sua obra, o presente artigo perpassa os três estágios demarcados por Kierkegaard que delineiam o agir do indivíduo, a saber, o estágio estético, o ético e o religioso. Então, a noção de indivíduo para o autor será esmiuçada, quesito central para a relação entre Kierkegaard e a Psicologia. Na sequência, temas caros ao autor, como a verdade objetiva e a verdade subjetiva, assim como a angústia e o desespero serão tratados de modo a poder nos fornecer possíveis relações com a psicologia e o fazer psicológico, relações essas que podemos inferir através dos temas que marcam 0 empreendimento kierkegaardiano.
\end{abstract}

Palavras-chave: Kierkegaard, Psicologia, Subjetividade.

\section{ABSTRACT}

This article approaches to the lived existencialism of Sören Kierkegaard, and indicates some important matters for a relation with Psychology. Starting with his biography, that is of vast importance to understand his works, this present article per passes the three stages delimited by Kierkegaard that guide the acting of the individual, to know, the esthetic, the ethic and the religious stages. Then, the notion of individual for the author is detailed, a central key for the relation between Kierkegaard and Psychology. Following, dear matters to the author, such as objective and subjective truth, as well as anguish and despair are treated in such a way that allows us to establish relationships with psychology and the psychological doing, these relationships that we could infer through the themes that mark the kierkegaardian undertaking.

Keywords: Kierkegaard, Psychology, Subjectivity. 


\title{
1 I ntrodução
}

Sören Kierkegaard (1813-1855) foi antes de tudo um escritor, publicando diversas obras no século XIX. Com um estilo marcado por metáforas e profundamente sarcástico, não escreveu sobre o mundo, nem elaborou um sistema explicativo deste; preocupou-se com a vida humana, a existência e com o ser-existente, ou seja, trabalhou com temas existenciais, tais como o desespero, a fé, o amor, a angústia, a ironia e outros.

Podemos considerar Kierkegaard como o fundador da filosofia da existência (WAHL, 1949 [1947], p.3), mesmo que os manuais de filosofia tradicionalmente apontem-no - ao lado de Nietszche - como um dos "pais" ou um dos precursores das filosofias da existência (JOLIVET, 1961; REALE; ANTISERI, 1990). Seu principal objetivo não era construir uma filosofia que buscasse uma essência, como em Platão, Spinoza e Hegel (WAHL, 1949 [1947], p.2), mas sim discorrer acerca da existência concreta (FEIJOO; PROTASIO, 2011) e com a temática do tornar-se cristão, visto que ele mesmo afirma que toda a sua obra se relaciona com o cristianismo e com um tornar-se cristão (KIERKEGAARD, 2002, p.24). Pensadores da existência que vieram após Kierkegaard, como Jaspers, Heidegger e Sartre construíram, no entanto, uma filosofia existencial propriamente dita, e certamente foram influenciados pelo "pai" do existencialismo.

Jean WAHL (1949 [1947]) faz um contraste entre as concepções clássicas de filosofia, como encontradas em Platão, Spinoza e Hegel em relação à filosofia da existência de Kierkegaard ${ }^{1}$. Em termos gerais, os filósofos buscavam ir acima da esfera do tornar-se a ser e encontrar uma verdade universal e eterna, por meio da razão. WAHL (1949 [1947]) considera Hegel como o último desses filósofos, ademais, ele nos diz:

\begin{abstract}
Hegel acreditava em uma razão universal. Ele nos conta que nossos pensamentos e sentimentos têm significado unicamente porque cada pensamento, cada sentimento, está amarrado à nossa personalidade, a qual tem significado apenas porque tem um lugar na história e no estado, em uma época específica na evolução da Idéia universal. Para compreender qualquer coisa que acontece em nossa vida interior devemos ir à totalidade que é o nosso eu, dali à totalidade maior que é a espécie humana e finalmente à totalidade que á a idéia absoluta (WAHL, 1949 [1947], p. 3).
\end{abstract}

É essa concepção que Kierkegaard veio a contradizer. Kierkegaard propôs a noção de que a verdade está na subjetividade, que a existência verdadeira é alcançada pela intensidade do sentimento (WAHL, 1949 [1947], p. 4). Essa subjetividade é a subjetividade do Indivíduo, pela qual ele ataca o sistema hegeliano (REALE; 
ANTISERI, 1990, p.240). "A existência corresponde à realidade singular, ao Indivíduo (o que Aristóteles já ensinou); ela permanece de fora e de qualquer forma não coincide com o conceito [...]. Um homem singular certamente não tem existência conceitual" (KIERKEGAARD citado por REALE; ANTISERI, 1990, p.241). Essa pode ser uma das maiores contribuições de Kierkegaard à psicologia, de procurar "focar em nossa irrepetível e insubstituível singularidade" (REALE; ANTISERI, 1990, p.241). Afinal, "o sistema não consegue engaiolar a existência" (REALE; ANTISERI, 1990, p.241), fazendo com que o elemento central de sua proposta seja a existência concreta, a "vida mesma" (FEIJ OO; PROTASIO, 2011, p. 13).

Para a compreensão da sua obra, que ele considera ser uma exposição cristã, não é necessário ser cristão, mas nunca se deve esquecer o local de onde tais palavras foram ditas (KIERKEGAARD, 2006 [1849], p.13). Em seu pensamento fica claro que as "ciências imparciais", ou aquelas que não têm o método existencial, não podem ser consideradas como sérias, sendo farsa e vaidade. Oposto às "ciências imparciais" está o indivíduo, que na terminologia de Kierkegaard, ousa ser ele próprio, é perante Deus, isolado em seu esforço e responsabilidade, um existente.

Entre as diversas formas de existência que Kierkegaard enumera, o ápice é aquela vivida pelo indivíduo cristão. "A diferença entre o homem natural e o cristão é o semelhante à da criança e do adulto" (KIERKEGAARD, 2006 [1849], p.16). Aquilo que faz a criança tremer não faz o adulto tremer, pois a criança vive em ignorância, como o homem natural. Ser cristão é - para Kierkegaard, sob uma perspectiva teológica - a forma por excelência de existir. "Ser cristão é sê-lo como espírito, é a inquietude mais elevada do espírito, é a impaciência da eternidade, é temor e tremor contínuo" (KIERKEGAARD, citado por REALE; ANTISERI, 1990, p.238).

Reale e Antiseri (1990, 2005) aferem que o pensamento de Kierkegaard é um pensamento essencialmente religioso: "é a defesa da existência do Indivíduo, existência que só se torna autêntica diante da transcendência de Deus".

Para um autor que viveu pouco (até os 42 anos), escreveu muito: seus escritos foram organizados em 22 volumes e mais cinco mil páginas de diários, totalizando mais de 10 mil páginas. Tendo nascido em uma pequena cidade provinciana, no centro intelectual da Escandinávia, teve algumas aulas com Schelling, o que the causou muito interesse. Respondeu a Hegel, tentando demonstrar que a vida, ou a existência, não pode ser restrita por um sistema. Foi esta defesa da categoria da "vida", em contraste com a valorização do "racional", que colocou Kierkegaard na vanguarda do debate existencialista.

Em meio a revoluções, Kierkegaard era famoso em sua época na Dinamarca. O alcance de sua obra, no entanto, não ficou limitado ao 
seu século ou país, tendo influenciado grandemente muitos pensadores atuais, especialmente após o declínio dos valores iluministas, quando os sistemas filosóficos racionais (dos "pensadores objetivos", na terminologia kierkegaardiana) não mais demonstravam compreender os fatos que aconteciam no mundo, tal como a Primeira e a Segunda Guerra Mundial. Nesse período, a filosofia do pensador da existência começou a ter um lugar privilegiado na esfera intelectual.

Certamente ele estava à frente de seu tempo, por ser o primeiro autor que veio a ter um olhar mais subjetivo acerca do ser humano: conseguindo retirar o homem como mero pertencente a uma espécie e colocando-o como definidor de sua existência. Seus seguidores, aqueles que desenvolveram e desdobraram seu pensamento, como Heidegger e Sartre, vieram somente após meio século da sua morte, no desenvolvimento científico que ocorreu no início do século XX.

Sua obra influenciou o mundo que estava por vir. Ao influenciar pensadores como Marcel, Jaspers, Buber, Sartre e Heidegger, seu foco no indivíduo trouxe um novo posicionamento perante o homem, e permitiu aprofundar nosso conhecimento sobre os elementos constitutivos do ser humano, como a angústia. Com seu pensamento, Kierkegaard expôs o homem a si mesmo. Tentou vivenciar cada possibilidade ao máximo, o que resultou em diversos pseudônimos, cada um com um tom diferente da existência. Essas "existências" (aqui representadas por seus pseudônimos) influenciaram 0 pensamento alemão antes do fim do séc.XIX e o pensamento francês entre as duas guerras (BEAUFRET, 1976 [1971], p.14).

Além do existencialismo, que tem suas origens da obra kierkegaardiana, podemos ainda notar as influências de Kierkegaard em outros contextos, tais como a Escola de Frankfurt. Theodor Adorno (1903-1969) reconhece ter sido influenciado a ponto de escrever sua tese de doutorado sobre o estético em Kierkegaard. Emmanuel Hirsch (1886-1972) tentou adaptar o existencialismo cristão de Kierkegaard para um nacionalismo alemão; Herbert Marcuse (1898-1979) percebeu em Kierkegaard uma raiz para uma teoria social (HANNAY; MARINO, 2006, p.1).

Autores como Rainer Maria Rilke e Franz Kafka entenderam a significância da sua obra (HALE, 2002, p.3). Teólogos certamente foram influenciados, visto que o próprio KIERKEGAARD afirma que sua obra se foca no tornar-se cristão (KIERKEGAARD, 2002). Marino (2006) afirma ainda que O Conceito de Angústia - uma das mais marcantes obras de Kierkegaard - foi de "enorme influência" ( $p .308$ ) em Paul Tillich, Karl Barth e Reinhold Niebuhr. Na sociologia, Hannay e Marino (2006, p.2) afirmam que Kierkegaard foi lido no círculo de Max Weber, e aceito tanto por agnósticos quanto ateístas. Wittgenstein afirmou que ele foi o pensador mais profundo do século XIX. 
Ademais, Martin Buber, referência obrigatória às psicoterapias de base humanista, conhecia a filosofia de Kierkegaard, e aponta para a singularidade do indivíduo; mas seu conceito base, que é a pessoa, aponta para uma individualidade singular, que está em contato com o mundo, em reciprocidade real com o mundo. Sobre o conceito de "indivíduo" em Kierkegaard, Buber chega a afirmar que a compreensão de tal conceito só seria possível a partir do entendimento de sua própria solidão, já que o indivíduo é a singularidade concreta que se encontra em si mesmo (BUBER, 1982). $\mathrm{O}$ foco de Kierkegaard sobre o indivíduo marcou profundamente $\mathrm{O}$ movimento da filosofia e do pensamento ocidental, pois sua filosofia deixou de buscar um sistema para explicar um sujeito objetificado. Para Kierkegaard, o indivíduo é superior à espécie (KIERKEGAARD, 1968 [1844]) e "a individualidade é o eixo de tudo" (KIERKEGAARD, citado por BEAUFRET, 1976 [1971], p.60), ocorrendo uma reversão de relação espécie-indivíduo ${ }^{2}$. Aqui certamente a afirmação de que sua obra é um reflexo de sua vida é válida, pois no humano, o indivíduo é superior à espécie. Também com isso, Kierkegaard abriu espaço para um método de ciência baseado na individualidade, na unicidade da existência.

Esse foco é um dos temas centrais desse trabalho, que parte de um ponto de vista que procura ler Kierkegaard como um contribuinte à psicologia. Para poder focar nas contribuições do pensamento kierkegaardiano à psicologia, primeiramente trataremos da biografia do autor, relevante para a compreensão da influência de sua vida pessoal na sua obra. Influência essa que baseia o próprio método existencialista, a partir do qual serão tecidas algumas considerações sobre suas contribuições para a psicologia: o pensador subjetivo, a angústia e o desespero. Dessa forma será possível verificar fundamentos para uma clínica psicológica a partir de Kierkegaard.

\subsection{Kierkegaard: A Pessoa, O Sujeito}

Sören Aabye Kierkegaard nasceu em Copenhague, Dinamarca, em 5 de maio de 1813. Certamente a maior influência em sua vida foi seu pai, Mikaël Pedersen Kierkegaard, como apontam as diversas biografias do filósofo (JOLIVET, 1952; BRANDT, 1963; MESNARD, 1986; REALE; ANTISERI, 1991; STRATHERN, 1999). Kierkegaard pai era servo de um sacerdote luterano local na Jutlândia (norte da Dinamarca), e trabalhava nas terras de seu dono. Provavelmente daí provenha o sobrenome Kierkegaard, como "a forma dinamarquesa do inglês churchyard [adro ou pátio de igreja, usado como cemitério]" (STRATHERN, 1999, p.15). Sempre foi um homem religioso. No entanto, houve um episódio que marcou sua vida, quando, em desespero, colocou-se sobre uma rocha na encosta e amaldiçoou a Deus. 
Após esse fato, um tio de Mikäel o levou para trabalhar consigo em uma loja de artigos de lã. Foi um excelente vendedor, e quando o tio morreu, herdou a loja, adquirindo uma razoável fortuna. Em contrapartida, sua mulher morreu logo após Mikäel ter se casado com ela, somente dois anos após o casamento. Poucos meses após a morte de sua primeira esposa, Mikäel tem relações com sua criada Ana Sörensdatter Lund, e Kierkegaard filho considera isso como o "pecado com Betsabéia" (referência ao adultério que Davi comete com Betsabéia, descrito na Bíblia em 2a Samuel 11). Em seguida Mikäel casa com a criada e tem sete filhos desse casamento. Em 1834, a segunda esposa morreu, quando Sören tinha 21 anos. Entre os irmãos de Sören, cinco deles faleceram até 1834 (alcançando a idade máxima de 34 anos). Apenas ele e Peter eram vivos. Ele próprio achava que iria viver até os 34 anos de idade (como os irmãos), e acabou vivendo até os 42 anos de idade.

Foi o preferido do pai, que o instigava a defender cada afirmação que fazia, aprendendo a lógica desde cedo. Seu pai lhe contava minuciosas descrições de diferentes lugares (os quais nunca tinha visto, mas apenas lido), e então, Sören era obrigado a relatar tudo o que via em sua mente.

$\mathrm{Na}$ juventude, participava das discussões que seu pai tinha com amigos, a partir das quais Kierkegaard aprende teologia, ética e o método da dialética. Em relação à sua aparência, pode-se dizer que Kierkegaard era extraordinário. Ligeiramente corcunda, tinha calças em que uma perna era mais comprida que a outra, e atraía a zombaria de colegas da escola. Defendia-se com um sarcasmo agressivo. Como escreve Strathern (1999) um "complexo de mártir" - acompanha por toda a vida, importante característica também refletida em seus escritos.

Em 1834 e 1835, foi para uma praia, para clarear seus pensamentos, entre suas anotações há uma frase que o acompanha pelo resto de sua vida: "o que importa é achar uma verdade, que é verdadeira para mim, para achar a idéia pela qual vou viver e morrer" (KIERKEGAARD, citado por JOLIVET, 1952, p.30). Essa verdade a que Kierkegaard se refere é a própria questão da subjetividade (BRANDT, 1963, p.64).

Ainda jovem, decide estudar teologia. Em 1836, apartou-se de seu pai, após descobrir erros do seu passado. Saiu de casa, adquiriu dívidas e entregou-se aos prazeres da vida. De 1837 a 1838, encontrava-se "cada vez mais enfermo, desconcertado e abatido" (KIERKEGAARD conforme citado por J OLIVET, 1952, p.35). Em 1838, Sören teve uma experiência espiritual, que ele próprio define como "o grande terremoto" (BRANDT, 1963). Jolivet (1952) e Mesnard (1986 [1953]) afirmam que esse evento remetia ao fato de haver Kierkegaard descoberto que seu pai amaldiçoou a Deus. Mesnard 
(1986) diz que Kierkegaard acredita que isso trouxe à sua família e a si próprio uma maldição.

Três meses antes de seu pai falecer, Kierkegaard volta a fazer as pazes com Mikäel. Também nesse momento, começa um fervor cristão, um novo estado de alma. Volta então a sentir alegria:

\begin{abstract}
Há uma alegria indescritível, que emana através de nós tão inexplicavelmente como quando irrompeu do Apóstolo sem aparente motivo: "Alegrai-vos, e novamente vos digo: alegrai-vos". Não uma alegria sobre isso ou aquilo, mas um grito sincero de toda alma "com a língua e boca e do fundo do meu coração" (KIERKEGAARD citado por BRANDT, 1963, p. 14).
\end{abstract}

O ano de 1840 é representativo para o pensador. Nesse ano, passa no exame de teologia, e opta pelo casamento, ficando noivo de Régine Olsen com um amor sincero e profundo, como diz Jolivet (1952). No ano seguinte, em setembro de 1841, defende sua tese sobre O Conceito de Ironia.

Era necessário, no entanto, que ambos vivessem de forma que a religião estivesse no centro de suas vidas. Por esse motivo, Kierkegaard escreveu diversos livros edificantes para a sua amada. Mas Régine não parecia disposta a seguir esse caminho da mesma forma que Sören. Kierkegaard então acaba por romper o noivado, já que não poderia existir uma comunhão espiritual entre ambos (JOLIVET, 1952). A respeito do noivado, Mesnard (1986 [1953]) aponta que diversas obras são dominadas pela figura de Régine e procedem diretamente da crise do noivado (como Ou-ou, Temor e Tremor, O Conceito de Angústia, Os Estágios no Caminho da Vida), o que indica que Régine também foi figura importantíssima em sua vida.

As influências podem ser vistas em suas obras, cada uma sob um nome diferente, e cada uma demonstrando um aspecto da existência de um ponto de vista diferente. Podemos interpretar cada pseudônimo como um existir individual, singular, e que cada sujeito pode escolher uma verdade para acreditar. Essa verdade irá influenciar a sua vida como um todo, pois, em Kierkegaard, vida e verdade coincidem, ou seja, aquilo que se acredita é aquilo que se vive, tomando isso como premissa.

\title{
1.2 A Questão dos Pseudônimos
}

Kierkegaard publicou seus livros sob diferentes pseudônimos, cada um deles demonstrando um aspecto ou ponto de vista com respeito à existência, aos diversos modos de existir. Kierkegaard considerava cada pseudônimo uma filosofia de vida e: "por uma 'filosofia de vida' Kierkegaard compreendia não apenas algo que alguém tinha uma 
opinião, mas algo que alguém vivia, algo que alguém realizava" (BRANDT, 1963, p.27).

Segundo Brandt (1963), "os escritos pseudônimos são a maior e mais valiosa conquista de Sören Kierkegaard. Filosofia, arte e teologia estão unidas de uma forma nunca antes vista" (p.26). Mas para que se utilizar pseudônimos? Para Strathern (1999), por desejar esconder-se, por um lado, "mas ao mesmo tempo queria deixar óbvio que era um pseudônimo (ou uma série de pseudônimos)" (p.26). Esse pseudônimo sempre seria de ordem estética (KIERKEGAARD, 2002) para, por meio da estética, atrair os olhares dos seus leitores:

\footnotetext{
Descreve o mundo estético com todos os seus encantos, cativa, se possível, o teu interlocutor, mostra este mundo mudando o tom da paixão que convém a esse homem, petulante se é jovial; triste se é melancólico; espirituoso se gosta de belas palavras (KIERKEGAARD, 2002, p.46).
}

Cada um de seus pseudônimos possui características diferentes e são destinados a leitores diferentes. Feijoo (2007) afirma que Kierkegaard "precisava mostrar-se de modo a agradar o outro, assim, ganhando o seu interesse, poderia então avançar em seu plano" (FEIJOO, 2007, p. 111). Brandt (1963) afirma que por meio dos escritos pseudônimos, a "sua intenção era de demonstrar uma série de diferentes pontos de vista sobre a vida, o que ele também chamou de 'Estágios da Vida', por autores fictícios" (BRANDT, 1963, p.23). A fim de organizar a sua estratégia de comunicação indireta, Kierkegaard utiliza-se de pseudônimos para assinar o conteúdo de suas obras, elaboradas de acordo com critérios estéticos, éticos e religiosos da existência humana.

Para Feijoo e Protasio (2011), os pseudônimos refletem uma obra multifacetada, "em uma polifonia de vozes e disposições afetivas que colocam, insistentemente o problema da existência" (p. 19).

Há, pois, um sentido "estético" para cada pseudônimo, mas igualmente um sentido "psicológico" para cada um deles, cada qual sendo um modo de apresentação de si ao mundo, de diferentes formas, como facetas de uma múltipla personalidade. Cada uma de suas obras é elaborada de acordo com um dos três estágios da existência humana, permitindo ao autor alcançar pessoas de todos os estágios (FEIJOO, 2008). Entretanto, compreender o significado dos pseudônimos não é uma tarefa fácil. Jolivet (1952) diz que seus pseudônimos são "tão numerosos quanto complicados" (p.23); e sempre temos de lembrar quem está falando e de onde se está falando (BRANDT, 1963, p.37).

O primeiro livro com pseudônimo (nesse caso "pseudônimos", pois a autoria é de alguns de seus pseudônimos) foi Ou isso ou aquilo: Um fragmento da vida, publicado por Victor Eremita que - assinala 
Strathern (1999) - tem um sobrenome que "provém da palavra grega antiga significando solitário ou proscrito" (p.26). Kierkegaard (2002) afirma que havia um pensamento enclausurado nesse nome, a escolha feita por ele, dentre as seguintes opções: "Precisava, ou de me precipitar no desespero e na sensualidade, ou de escolher absolutamente o religioso como a única coisa necessária, ou o mundo numa medida que se anunciava cruel, ou o claustro" (KIERKEGAARD, 2002, p.35).

Visto que havia terminado o noivado, fica óbvio o motivo da escolha por tal nome e qual opção ele tomou, de se tornar um recluso no mundo, optando pelo religioso. No final da primeira parte desse livro, há um texto intitulado O Diário de um Sedutor, no qual o autor é Johannes ${ }^{3}$, o sedutor. Brandt (1963) considera o livro como "uma penetrante peça de psicologia". Essa parte do livro contém cartas de amor de Kierkegaard e Régine Olsen.

J ohannes de Silentio escreveu Temor e Tremor, onde KIERKEGAARD se denomina um "observador sério disposto de pressupostos religiosos [...] de quem é possível fazer-se compreender à distância, ao qual se pode falar no silêncio (o pseudônimo: Johannes... de Silentio)" (KIERKEGAARD, 2002, p.37). Afirma não ser filósofo, nem construir um sistema, mas sim um "poeta e elegante", para quem escrever é um luxo que quanto menos leitores tiver, mais significativo é. "É um livro fácil de ser lido à hora da sesta" (KIERKEGAARD, s/d, p. 3).

Victor Eremita e Johannes de Silentio foram os pseudônimos que introduziram os estágios na obra de Kierkegaard. Ou-ou retrata os estados estético e ético, enquanto que Temor e Tremor retrata o estágio religioso. Kierkegaard ainda usaria outros pseudônimos - que citamos a seguir: Constantin Constantinus, Vigilius Haufniensis, Johannes Climacus, Nicolaus Notabene, Hilarius Bookbinder, Frater Taciternus (Irmão Taciturno) - mas dada a relevância dos dois supracitados, estaremos nos atendo a estes.

De 1842 a 1846, Kierkegaard publicou paralelamente a seus escritos de pseudônimos, dezoito discursos edificantes sob seu próprio nome. BRANDT (1963) interpreta que Kierkegaard escreveu esses escritos em seu nome porque demonstravam um ponto de vista cristão da vida, pelo qual ele poderia se responsabilizar. Quando Kierkegaard utilizava seu próprio nome, escrevia de um ponto de vista religioso, com o qual seu falecido pai concordaria. Tanto é que dedicou esses dezoito discursos ao seu pai (BRANDT, 1963).

Cada pseudônimo, no entanto, não foi somente uma mera criação intelectual sua. Eles estavam intrinsecamente relacionados com acontecimentos e experiências adquiridas durante a sua vida, e foram, portanto, reflexos de sua própria subjetividade. 


\subsection{As Obras como Reflexo da Vida}

Os livros que Kierkegaard escreveu podem ser lidos como expressões do existir, que encontram paralelos com sua vida pessoal, embora não se tenha acordo com respeito a essa questão. Mas certamente podem ser compreendidos como metáforas que refletem a vida em si, ou seja, a própria existência. Sendo assim, suas obras reportam às dimensões do existir. No entanto, Kierkegaard não é de fácil compreensão, pois ele mesmo afirma que a sua vocação era de "fazer as coisas mais difíceis" e de "criar dificuldades em todas as partes" (KIERKEGAARD, citado por J OLIVET, 1952, p.17).

No livro Temor e Tremor, Kierkegaard trata da questão da fé, a partir da história de Abraão, que deve sacrificar seu filho Isaac. Para Abraão havia um conflito entre uma lei divina (a de não cometer assassinato) e uma ordem que ele entendia que havia recebido de Deus, a de sacrificar seu filho a Deus em um altar. Kierkegaard, durante seu noivado, sentiu que deveria deixar sua noiva e não se casar, para poder dedicar-se à sua autoria com mais finco. No entanto, Régine havia dito que se Sören fosse terminar o relacionamento com ela, ela iria se suicidar. Kierkegaard então se sente numa posição análoga à de Abraão: se ele ouvisse a voz divina estaria cometendo assassinato com sua noiva, desobedecendo assim outra lei divina. Contudo, a resolução que Kierkegaard chegou foi a de terminar seu noivado para dedicar-se à sua autoria (atendendo então ao chamado divino), e obtendo sobre si um fardo de culpa devido ao possível suicídio da noiva. Posteriormente esse fardo é aliviado quando Régine casa com outro homem.

Entweder-Oder ${ }^{4}$, livro ainda não traduzido para o português, conta sobre duas formas de se viver a vida: Ou de forma estética, Ou de forma ética (por isso o nome do livro ser "Ou isso ou aquilo"). Já O Conceito de Angústia, de 1844 é uma obra de "antropologia religiosa", nas palavras de Aranguren (1982), onde a ideia principal remete ao estado de Adão antes do pecado original. A angústia é um "estado afetivo" que não reflete uma imperfeição, mas o "lugar psíquico mesmo da irrupção do espírito. Angústia como suposto do pecado original (...), conseqüência dele também, (...) mas assim mesmo, abertura para a fé" (ARANGUREN, 1982, p. 10). Como Adão é "simultaneamente ele mesmo e o gênero humano" (KIERKEGAARD, 1968 , p. 33), toda a humanidad passa pela angústia. OSTENFELD (1978) afirma que com esse livro, Sören retrata a questão dos pecados do pai de Kierkegaard, e a possível herança deles por Kierkegaard. O livro é "uma repercussão das experiências chocantes no seu estreito círculo de parentes, refletido em uma mente que era incondicionalmente presa a uma família vivendo sob aquela nuvem e consciente de suas próprias peculiaridades" (OSTENFELD, 1978, p. 20). 
Em Migalhas Filosóficas, ensaio publicado por Johannes Climacus em 1844, Kierkegaard aborda o problema da comunicação. Jolivet (2000) afirma que, nesta obra, Kierkegaard aponta para uma "comunicação direta [que] transmite um saber", e uma "comunicação indireta [que] dirige-se, ao contrário, à subjetividade profunda, à interioridade, e sua tarefa; e despertar no indivíduo a consciência do existencial, do eterno, do dever" (p. 374). Essa "transmissão de um saber" aponta, todavia, para a incompreensibilidade do "objeto" que comunica, ou seja, não é possível transmitir ao homem sua interioridade e sua existência; portanto, opõe-se ao saber objetivo e "conciliador" que age como um "sedativo" (JOLIVET, 2000). Essa comunicação é inquieta e como tal, remete ao caráter dramático da existência. Aqui, Kierkegaard opõe-se a Hegel naquilo que o pensador idealista "concilia", enquanto que "Kierkegaard insiste em sua ruptura radical" (JOLIVET, 2000, p. 10). Ainda segundo Jolivet (2000), essa obra de difícil compreensão tem um complemento explicativo em PostScriptum Definitivo e Não Científico às Migalhas Filosóficas, publicado em 1846, onde Kierkegaard destaca o drama da existência humana, reiterando seu caráter trágico e a questão do desespero. "É no PostScriptum que Kierkegaard desenvolve o termo 'existencial'. Essa palavra aparece em seu diário, mas é aí que assume sentido radical e de algum modo ofensivo" (JOLIVET, 2000, p.436).

Em O Ponto de Vista Explicativo de Minha Obra, de 1848, Kierkegaard tece explicações sobre a sua posição como autor. Comenta sobre sua produção pseudônima e de própria autoria, deixando claro sua posição religiosa, sem a qual não faz sentido a sua obra. O Desespero Humano, de 1849, coloca a questão do homem perante Deus e perante Cristo, passando pela questão do pecado e da fé. Em 126 páginas, observações psicológicas, filosóficas e teológicas são escritas sobre o desespero, ou "a enfermidade mortal" - nas palavras de Kierkegaard - como próprio à pessoa humana, e que aponta para a precariedade de sua existência. Nas palavras de Abbagnano (1992), "enquanto a angústia se refere à relação do homem com o mundo, o desespero se refere à relação do homem consigo mesmo" (p. 309), o que aponta para sua finitude. Essa obra tem como subtítulo Doença até a morte ${ }^{5}$.

Desespero é a impossibilidade de cada um se aceitar como é: nosso eu, em sua tentativa de autenticidade, choca-se com o desespero. Apesar de tudo, essa consciência desesperada - pois é autoconsciência - "nos põe acima do animal"; e se o homem é superior ao animal, o cristão, consciente de seu desespero, é um homem superior [...]. É preciso desesperar, pois a "perdição" permite a remissão: é preciso, para não mais desesperar (JOLIVET, 2000, p.116).

Todas as suas obras abordam diferentes aspectos, ou possibilidades de existência, como diz o próprio Kierkegaard no prefácio de $\mathrm{O}$ 
Conceito de Angústia: "No meu entender, aquele que desejar escrever um livro deverá meditar, sob os mais diferentes aspectos, a respeito do que pretenda escrever" (KIERKEGAARD, 1968, p.13). No entanto, todas as obras têm um mesmo olhar sobre o homem, que nos remete à concepção de subjetividade, de sujeito existencial. Esse ponto de vista inclui a noção de que o homem é superior à espécie, bem como a idéia de que a verdade está na subjetividade, e remete a uma idéia de homem, que merece explicitação.

\title{
2 A I deia de Homem em Kierkegaard
}

\begin{abstract}
O homem é espírito. Todavia, que é espírito? É o "eu". Mas, nesse caso, o "eu"? O "eu" é uma relação que não se estabelece com qualquer coisa de alheio a si, mas apenas consigo mesma. Ele consiste no orientar-se dessa relação para a própria interioridade, mais e melhor do que na relação propriamente dita. Não é a relação em si, o "eu", mas, sim, o seu voltar-se sobre si mesma, o conhecimento que ela tem de si mesma depois de estabelecida (KIERKEGAARD, 2006, p. 19).
\end{abstract}

Em Kierkegaard, o homem é espírito. E o espírito é caracterizado como uma autorreflexão, que é um voltar-se para si, não no sentido de uma "reflexão-sobre", mas de uma "relação do homem consigo mesmo e nisto consiste precisamente o eu" (ABBAGNANO, 1992). Podemos compreender isso como um voltar-se para a própria relação, que faz com que o homem exista.

Mas não só isso, "o homem é uma síntese de infinito e de finito, de temporal e de eterno, de liberdade e de necessidade, é, em resumo, uma síntese" (KIERKEGAARD, 2006, p.19). Nota-se aqui o paradoxo e a dialética da existência, demonstrando que o eu não é somente finito, com escolhas limitadas, mas também infinito, podendo escolher uma infinidade de caminhos a seguir. Como aponta Protasio: "O finito (concreto) delimita a existência, e o infinito (ideal) ilimita o homem, abrindo-o para todas as possibilidades" (PROTASIO, 2008, p. 16).

Kierkegaard afirma que o corpo é temporal e a alma é eterna, e aquilo que mantém ambos unidos é o espírito. E aqui novamente vemos o paradoxo entre o infinito e o finito: a alma eterna, que pode relacionar-se com Deus (infinito e eterno) e o corpo, temporal, concreto e preso a esse mundo. O espírito, o eu, é aquele que tem de realizar um equilíbrio entre ambas as partes.

Mas esse "eu" não é a união em si, mas um terceiro, que une alma e corpo quando reconhece a si mesmo (numa atitude que reconhece tanto o finito quanto o infinito em sua existência): 


\begin{abstract}
Quando dois termos se relacionam, a própria relação entra como um terceiro, como unidade negativa, e cada um daqueles termos se relaciona com a relação, tendo cada um existência separada no seu relacionar-se com a relação. Acontece assim com respeito à alma, sendo a ligação da alma e do corpo uma simples relação. Ao contrário, se a relação se conhece a si mesma, esta última relação que se estabelece é um terceiro termo positivo, e temos então o "eu" (KIERKEGAARD, 2006, p.19-20).
\end{abstract}

Com isso, Kierkegaard afirma que na união entre o finito e infinito cria-se um terceiro, o espírito. O espírito tem uma relação de cada lado, e os lados estão separados. Essa é a concepção como unidade negativa. A unidade positiva que Kierkegaard fala é quando ocorre o autorreconhecimento de si, que é quando temos o eu. Mesmo sendo igual o conceito e a universalidade do homem, a forma pela qual ele irá exercer o seu espírito, o seu eu, diferencia-se, de acordo com a atitude perante a vida. Essa diferenciação gerou o que Kierkegaard denomina de estágios.

\title{
3 Os estágios
}

Brandt (1963) aponta para um texto intitulado "Uma Primeira e Última Explicação", onde Kierkegaard reconhece sua autoria de todos os escritos pseudônimos. Também afirma que seu trabalho não pretende desenvolver algo novo, mas fazer uma releitura sobre os "escritos originais das condições individuais da existência humana" (KIERKEGAARD, citado por BRANDT, 1963). Kierkegaard faz uma análise do ser humano, esmiuçando-o até o último sentimento, concretizando o que ele descobriu em três diferentes estágios, cada um com suas especificidades individuais; cada estágio como um possível funcionamento do indivíduo.

Kierkegaard descreveu três pontos de vista diferentes: o estético, o ético e o religioso. Cada um desses estágios - ou, etapas, estádios, estações, esferas (FEIJOO; PROTASIO, 2011), para melhor designálos - é uma forma de existir (BRANDT, 1963). Além disso, cada estádio estabelece referenciais pelos quais o homem estabelece suas escolhas (FEIJ OO, 2008).

Uma importante advertência sobre os estágios da existência em Kierkegaard encontra-se em Mora (2001), quando diz que "como o estágio ético parece a negação do estético e o religioso a negação do ético, pode-se pensar que nos encontramos perante a tríade de caráter hegeliano regida por leis dialéticas" (p. 1644), portanto, não se trata de determinação racional. Assim, os três estádios não são distintos abstratamente, mas em determinações existenciais. "Por conseguinte, se há alguma 'lei' que rege as relações entre os três 
estágios, trata-se da lei da alternativa: ou um ou outro" (MORA, 2001, p. 1644). São alternativas existenciais e não racionais.

No primeiro estágio - estético - o prazer é o alvo da vida. Busca-se alegria momentânea, onde somente o "agora" importa. Nesse estágio não há um envolvimento profundo com relacionamentos, e vai-se contra obrigatoriedades, em constante mudança (BRANDT, 1963). Feijoo (2008) acrescenta ainda o descompromisso com o outro, onde o sujeito está sempre autocentrado, e se ilude acreditando que na existência há lugar somente para o prazer, mas isso não é possível, visto que a angústia está presente em toda a humanidade. No estágio estético existem possibilidades para tudo, sem restrições, porém sempre no plano do imediato. Existe um "absoluto selvagem do desejo, o vazio do dandismo ocidental" (MESNARD, 1983 [1953] p. 21). Kierkegaard escreveu deste ponto de vista quando usou o pseudônimo Johannes, o Sedutor, no livro Diário de um Sedutor, contendo cartas à sua noiva. Outro esteta é o "Esteta A" da obra Ouou, um jovem que está cansado na vida, melancólico e aparentemente sem futuro, que, ocasionalmente, vivencia momentos de beleza. Esse "Esteta A" é referência à própria vida de Kierkegaard quando este estava em sua juventude (BRANDT, 1963).

O estágio ético caracteriza-se pela responsabilidade e pelo dever, onde o casamento é uma obrigação. Enquanto o esteta vive no momento, o homem ético acredita que sua vida tem uma continuidade histórica. O fator decisivo é fazer uma escolha entre as categorias do bem e do mal, as categorias do ético (BRANDT, 1963). Feijoo (2008) comenta que o homem ético reconhece as consequências e responsabilidades de seus atos, e por isso vive de forma preocupada. "Corre o risco de perder-se de si mesmo nas solicitações impostas pelas regras. Ilude-se, pensando que pode construir uma existência idealizada, sem erros e imperfeições" (FEIJOO, 2008, p. 314), visto que uma metafísica (existência idealizada) não consegue abarcar toda a subjetividade humana.

Mesnard (1986 [1953]) afirma que o estágio ético "se trata a priori de um saber unitário e de uma vida coerente governada por normas morais" (p. 22), "é reconhecível massivamente pela organização material da existência segundo as normas universais da moral" (p.25). O juiz Wilhelm - personagem importante da obra Ou-ou, onde Kierkegaard demonstra ambos os estágios, estético e ético representa o estágio ético, defendendo o casamento, que implica em compromisso e moralidade.

O estágio religioso se caracteriza por uma profunda relação com Deus. A vida terrena, instantânea, não possui importância se for comparada com o futuro eterno de um homem religioso. Muito mais vale a pena investir seus esforços focando na eternidade religiosa do que com o breve da Terra. Enquanto que o esteta vive no momento e o ético vive no tempo, o religioso vive com sua atenção voltada ao 
eterno (BRANDT, 1963). O homem religioso prioriza a humildade. Ilude-se achando que alcançou um estado em que não é mais solicitado pelo mundo (FEIJOO, 2008), pois não é possível viver completamente na eternidade se se está preso ao mundo por meio de um corpo. Mesnard (1986 [1953]) afirma que o estágio "religioso é o apelo à subjectividade profunda, a devoção ao Deus escondido, e o silêncio que daí advêm" (p. 25).

No livro Temor e Tremor o estágio religioso é comentado pela primeira vez. Nele, Kierkegaard demonstra que o plano moral não é o absoluto, por meio da história do sacrifício de Abraão (demonstrando assim um plano religioso acima do plano moral). Tal como Abraão foi restituído de seu filho quando demonstrou que estava disposto a sacrificá-lo devido às ordens divinas, existia a possibilidade de Kierkegaard recuperar a noiva que havia perdido, visto que ele a abandonou em prol de seu chamado divino de ser um escritor (MESNARD, 1986 [1953]).

Importante se pensar os estádios como "diferentes possibilidades de existir" ( $p .14$ ), ao invés de etapas a serem superadas, que reteriam um "elemento teleológico-superior-ideal" (p. 15). Com isto, Feijoo e Protasio (2011) pretendem apontar a direção da consideração dos estádios como tensão, justificando sua hipótese na premissa de que "as obras estéticas estiveram presentes até o final de sua produção, assim como as obras religiosas estiveram presentes desde o início" (p. 17). Esta posição é ratificada por Farago (2006), quando aponta para a noção de etapa como um "estilo de vida". Portanto, os estádios são possibilidades de existência, o que revelaria a "sutileza do projeto kierkegaardiano" (FEIJOO; PROTASIO, 2011, p. 17).

A passagem entre os estágios é realizada somente por meio de um “salto" (JOLIVET, 1953), pois cada estágio caracteriza-se por uma perspectiva diferente. Kierkegaard ressalta que não há uma necessidade nesse "salto", nem logicamente ou psicologicamente (BRANDT, 1963). "Salto" é uma metáfora kierkegaardiana para o movimento da existência, "movimento essencialmente distinto do devir lógico-metafísico propugnado por Hegel" (MORA, 2001, p. 2582), o que seria - na perspectiva hegeliana - uma transição. Em Kierkegaard, o "salto" remete a uma ruptura, que é essencial (MORA, 2001; FEIJ OO; PROTASIO, 2011).

\section{Elementos para a psicologia a partir de uma vivência pessoal}

Kierkegaard não foi de fato um filósofo. Strathern (1999) comenta que para os puristas, Kierkegaard foi o primeiro antifilósofo do existencialismo (por não fazer nem uma metafísica nem uma ontologia). O próprio Kierkegaard, ou melhor, um de seus pseudônimos, Johannes de Silentio, diz que "o presente autor de 
modo algum é um filósofo. Não entendeu qualquer sistema de filosofia, se é que existe algum, ou esteja terminado" (KIERKEGAARD, s/d, p.3).

O primeiro autor do existencialismo não escreveu sobre o mundo, nem construiu um sistema racional. Falou acerca de si próprio e para si próprio:

[...] podemos alegar numerosos textos nos quais Kierkegaard declara que toda sua obra não é senão uma expressão de sua vida [...]. Toda a obra gira em torno de mim mesmo, única e exclusivamente em torno de mim mesmo (KIERKEGAARD citado por JOLIVET, 1952, p.31).

O que Kierkegaard escreveu certamente está relacionado com sua aprendizagem de vida, com tudo o que o influenciou, como diz: "Toda minha produção não é senão minha educação" (KIERKEGAARD, citado por JOLIVET, 1952, p. 31). Nisto se percebe um caráter "pessoal" ou "personalizado" de sua obra, o que aponta para sua perspectiva subjetiva e revela um modo de apreensão do exixtente. Pode isso ter sido um acidente? Certamente não. "Em Kierkegaard esta coincidência entre a vida e a obra se converte em uma lei, um princípio: o princípio do método existencial" (JOLIVET, 1952, p.10). Berdiaeff afirma que a filosofia de Kierkegaard é a expressão de sua existência: "Ele não queria criar uma ontologia ou metafísica, e ele não acreditava na possibilidade de uma filosofia ideacional, ele acreditava somente em uma expressão da existência" (BERDIAEFF, citado por WAHL, 1949, p. 36).

Jolivet demonstra que a filosofia deve apropriar-se reflexivamente da própria verdade e expressá-la tal como se vive concretamente; não pensar sobre a verdade, mas sim viver a verdade, e a verdade se vive no individual (J OLIVET, 1952).

Kierkegaard se utilizou de pseudônimos para expressar algumas dessas diferentes possibilidades. Ele se encarregou, como um "pensador existencial" de considerar essas possibilidades e de dar "comunicações da existência" sobre elas. O fator decisivo é que o pensador existencial não adota uma atitude meramente intelectual, de observador perante as várias formas de se viver a vida. Ele se entrega apaixonada e fervorosamente a essas possibilidades, e vive intensamente a "forma de existência" que ele escolheu (BRANDT, 1963).

Com um aporte que releva o emocional - o que faz com que Kierkegaard seja frequentemente associado a teorias e práticas psicológicas as mais diversas, como a Gestalt-Terapia, a Abordagem Centrada na Pessoa ou a Psicologia Existencial (MAY, 1967; PENNA, 1985; RIBEIRO, 1985; HOLANDA, 1998; PERES; HOLANDA, 2003; FEIJ OO, 2007; 2008; PROTASIO, 2008; PONTE, 2010) - o pensador 
dinamarquês se separa do pensador comum. O pensador existencial "prefere imergir no lado emocional da existência" (BRANDT, 1963, p.63). Esse pensador existencial foi chamado por Kierkegaard de 0 "pensador subjetivo" enquanto que o pensador em geral é chamado de o "pensador objetivo", o cientista.

\subsection{Verdade subjetiva vs. verdade objetiva}

A principal contribuição que Kierkegaard trouxe para a psicologia é uma leitura da subjetividade, o que nos permite discutir o sujeito da psicologia, não como um sujeito científico, "antropologizado", definindo todo o homem sob uma pequena lente, que segundo o autor, não conseguiria abarcar toda a existência. Mas sim um sujeito caracterizado pela sua individualidade a partir de uma subjetividade, um pensador subjetivo, que se baseia em uma verdade subjetiva. A essência da existência humana é o indivíduo: "o homem é indivíduo e, assim sendo, é ao mesmo tempo ele mesmo e toda a humanidade, de maneira que a humanidade participa toda inteira do indivíduo, do mesmo modo que o indivíduo participa de todo o gênero humano" (KIERKEGAARD, 1968 [1944], p. 32). É aqui que cada um tem a sua importância, pois o seu modo de existir afeta todo o gênero humano. Assim, temos um "pensador subjetivo" e um "pensador objetivo". O pensador objetivo difere do subjetivo, pois aquele vive fantasticamente em um mundo de abstração, deixando de lado as demandas da existência sobre si, acaba se perdendo em um mundo de especulação (BRANDT, 1963), pois tenta viver de acordo com um sistema, que, segundo Kierkegaard, nunca abarcará toda a experiência do indivíduo.

Quando Kierkegaard fala de verdade, prioriza a verdade subjetiva, e põe em dúvida se a pessoa vive de acordo com uma filosofia da vida que escolhe, compreendo-as - todas - como válidas e legítimas (BRANDT, 1963).

A verdade objetiva propõe uma verdade "científica", em que se estuda um objeto e a partir disso se constrói uma teoria para explicar o seu funcionamento, e se verifica no concreto se a ideia que se tinha a respeito de algo se mantém verdadeira perante fatos objetivos. Falar objetivamente implica em procurar provas para certas ideias, que só serão consideradas verdadeiras caso elas sejam testadas no mundo e se mostrarem adequadas. Como um exemplo simples de verdade objetiva, pode-se afirmar que a Terra é redonda, e as provas obtidas por meio de estudos e viagens ao espaço provam isso. Isso seria uma verdade objetiva, quando uma concepção (ideia ou teoria) concorda com o objeto: a Terra é "verdadeiramente" uma esfera.

Verdade subjetiva, em contraposição, depende de um existente individual, que escolhe uma filosofia de vida, e será verdade caso viva de acordo com essa sua filosofia de vida. Em certo aspecto, 
trata-se de uma verdade emocional e volicional que, como afirma BRANDT (1963), está ligada a uma vontade. "O que é a verdade se não viver por uma idéia? [Ademais], somente a verdade que edifica é verdade para você" (KIERKEGAARD, citado por BRANDT, 1963, p. 64).

Há forma de se conhecer a verdade entre os dois tipos de verdade. $\mathrm{Na}$ verdade objetiva se tem ideias e fatos acerca de um objeto, enquanto que na verdade subjetiva se sente a verdade, se acredita numa verdade, se escolhe uma verdade. Kierkegaard explica isso resumidamente, da seguinte forma: "Objetividade é uma questão de definições de pensamentos, subjetividade de interioridade" (KIERKEGAARD, citado por BRANDT, 1963, p. 66). Destaque-se que, tanto o apelo ao emocional, quanto ao volitivo não tornam Kierkegaard, necessariamente, um irracionalista.

A verdade objetiva busca conhecer um objeto e falar a verdade acerca dele. Fala-se do objeto ao qual se está relacionado. O foco não é a relação, mas a verdade contida no objeto. Por outro lado, a verdade subjetiva estuda a relação do indivíduo com o mundo, e "apenas quando o como dessa relação [do indivíduo com o objeto] está na verdade [ou seja, na verdade subjetiva] o indivíduo está na verdade, mesmo se ele é desse modo relacionado à inverdade" (KIERKEGAARD, citado por BRANDT, 1963, p.66).

Diversas linhas da psicologia (tais como a Gestalt-Terapia, a Abordagem Centrada na Pessoa ou a Daseinsanalyse) partem desse pressuposto, de que na terapia - por exemplo - o que o sujeito fala é sua verdade, enquanto reflexo de sua subjetividade, de sua experiência de vida, de sua vivência, ou seja, identifica-se com sua "verdade subjetiva" (ROGERS, 1961; MAY, 1967; RIBEIRO, 1985; HOLANDA, 1998; YONTEF, 1998; KARWOWSKI, 2005; PONTE, 2010). Sabe-se de antemão que aquilo que o sujeito da clínica traz, certamente está influenciado pela sua própria experiência, por seu histórico de vida, por sua criação ou pela suas escolhas. Em algumas dessas perspectivas clínicas - como a Gestalt-Terapia ou a Abordagem Centrada na Pessoa, por exemplo (RIBEIRO, 1985; HOLANDA, 1998; PERES; HOLANDA, 2003; PONTE, 2010) - acreditase que ao se mudar as escolhas, alterando-se as "filosofias de vida" ou aquilo que se tem por "verdade objetiva", igualmente se altera a "verdade subjetiva" - a verdade do sujeito - tendo como resultado uma transformação da própria relação do sujeito com seu mundo, e isto seria um dos possíveis caminhos para a própria clínica.

A verdade objetiva reflete uma verdade coletiva, da qual todos participam, enquanto que a verdade subjetiva foca em uma verdade singular e individual. "Objetivamente, o que é dito é acentuado; subjetivamente, como é dito" (KIERKEGAARD, citado por BRANDT, 1963). Falar em como implica em vivência, em entrar em contato 
com suas entranhas e escolher viver, o que quer que seja, desde que seja algo por que se possa viver e morrer.

O pensamento de Kierkegaard pode ser encarado tanto em sua perspectiva ontológica - marcando o caráter de indeterminação da existência - quanto por uma perspectiva ôntica, onde o sujeito (principalmente quando se pensa um "sujeito" da clínica, como em certas abordagens acima citadas) é chamado a se responsabilizar por suas escolhas e atitudes, que estariam baseadas naquilo que 0 sujeito acreditaria ser a verdade para si. Dado que esta escolha não é fácil, nem simples - pois a própria escolha implica em ter que fazer uma escolha e supor as diversas possibilidades de existir - advém a angústia.

\subsection{A Angústia}

Não é fácil conseguir traduzir o que Kierkegaard escreveu em sua obra O Conceito de Angústia em termos compreensíveis. Marino (2006) afirma este livro como "insanamente difícil" e que até mesmo os "estudiosos de Kierkegaard ficam quietos na maioria dessas passagens" que fogem à compreensão. Contudo, "se for preciso escolher somente um texto como livro base da psicologia existencial e da psicanálise, certamente seria O Conceito de Angústia" (p. 308). Em Kierkegaard, a questão da angústia é muito relevante, pois "pela falta de um projeto básico para a sua existência e pela ausência de uma essência definidora de si, é imposta ao homem uma liberdade absoluta que Ihe gera medo, insegurança e angústia" (PERES; HOLANDA, 2003, p. 102). Em Kierkegaard, a angústia remete a um "abismo irreconciliável entre o finito e o infinito (...), como um desamparo em que a subjetividade limitada do homem está suspensa no nada de seu angustiar-se" (MORA, 2000, p. 138), portanto, é uma indeterminação originária.

Segundo Kierkegaard (1968 [1844]), “a angústia é a realidade da liberdade como puro possível" (1968 [1844], p.45). Essa é a conceituação mais básica, simples e de grande aplicação. A possibilidade traz consigo a angústia, a liberdade acarreta em angústia. A angústia ocorre quando o homem confronta a liberdade. Ostenfeld (1978) comenta acerca da angústia:

Filosoficamente, angústia significa dúvida, não-vontade ou falta de coragem para experienciar auto-conhecimento existencial. Colocando de outra forma, Kierkegaard quer mostrar que a psicologia deve admitir que em toda situação de escolha há, apesar de certas determinações, a livre possibilidade de agir em duas direções (p. 19).

Ademais, Protasio (2008) aponta que "o objeto da Psicologia é a angústia, o sentimento de ambiguidade que antecede toda escolha, 
toda possibilidade" (p. 6), sendo ainda a base - ou estando na base de um número significativo de práticas e leituras psicológicas, como a Daseinsanalyse, ou as abordagens de orientação humanista e existencial.

Kierkegaard propõe um retorno a si mesmo, que alguns comentadores associam ao princípio socrático (PERES; HOLANDA, 2003) ou a um "salto" (ABBAGNANO, 1992; MORA, 2000). Esse retorno à sua própria subjetividade é saber que a verdade subjetiva é determinadora de ações. Com esse retorno, podemos afirmar que se cria um "eu" kierkegaardiano, ou seja, o indivíduo, um conhecimento de si e de sua situação. Justamente "a angústia seria a via de acesso à consciência de si, de sua situação" (PROTASIO, 2008, p. 8).

A partir da autoconsciência, o homem começa a ter um eu, o que em algumas abordagens psicológicas poderia ser comparado ao "aparecimento do ego". Essa mudança é um salto qualitativo, de um ponto de inocência e ingenuidade para um ponto de autoconsciência. May (1977, p.55) aponta que "através da autoconsciência, o homem pode moldar e, em certa medida, transformar o seu presente desenvolvimento histórico". Pela autoconsciência a angústia torna-se mais reflexiva, começa a ter mais significado.

No entanto, se não há um "eu" (indivíduo) para se ter noção das possibilidades, ali não haverá angústia, visto que se não há eu, é como se fosse um estado de inocência ou ignorância (KIERKEGAARD, 1968 [1844]). Ou seja, caso não se tenha feito uma escolha pela verdade pela qual se vai viver ou morrer ou nem se pensa nisso não há angústia, visto que não há necessidade nem possibilidade de escolha.

O próprio poder criativo pode ser angustiante, visto que o indivíduo pode constantemente se transformar. Kierkegaard deixa claro, no entanto, que fazer uma passagem de um estágio ao outro envolve uma completa mudança, um "salto na fé".

Fazendo uma breve ponte com autores que utilizam Kierkegaard para embasar uma clínica podemos afirmar que para Kierkegaard, quanto mais consciência, melhor. Para Rollo May, importante psicólogo existencialista americano, essa é uma das finalidades básicas da psicoterapia:

[...] ampliar a autoconsciência mediante o esclarecimento de
frustradores conflitos internos que existiam porque o
indivíduo foi forçado, em tempos anteriores a bloquear o
conhecimento de si mesmo. É claro que na terapia esses
bloqueios da autoconsciência ocorreram porque a pessoa foi
incapaz de superar as acumulações de ansiedade em vários
pontos de seu crescimento (MAY, 1977, p.55).

Kierkegaard verifica a angústia de vários pontos de vista diferentes, como por exemplo, na temporalidade, com a angústia do passado e 
futuro, que acontece no presente. A angústia do passado pode ocorrer da seguinte forma: "O passado, para me dar angústia, deve mostrar-se diante de mim como coisa de possível. Se eu sentir angústia por mal que passou, não há de ser por esse mal como passado e sim como coisa que pode ser reproduzida, isto é, que pode vir a ser futuro" (KIERKEGAARD, 1968 [1844], p.96).

\subsection{O Desespero}

Brandt (1963) cita o Diário de Kierkegaard, afirmando que o Desespero Humano é o livro mais verdadeiro e perfeito que Kierkegaard escreveu, e certamente é o mais profundo.

Segundo Protasio (2008) o desespero reside no caráter provisório e paradoxal da existência. Para Kierkegaard (2006 [1849]), o desespero se caracteriza em querermos ou não, sermos nós mesmos, e aí reside o caráter paradoxal da existência.

Um bom exemplo disso é o que Kierkegaard (2006 [1849]) demonstra no quinto capítulo do livro. Ele fala do cristão que peca e permanece no pecado. Via de regra, o cristão não peca, pois o pecado seria o oposto da fé. Considerar-se cristão, que é uma escolha, mas ao mesmo tempo pecar é uma das formas do desespero. "A existência humana, assim compreendida como desespero, efetiva-se cotidianamente sob a forma de ilusão, de um querer ser o que não se é, vivendo o constrangimento de não ser o eu que se ilude ser" (PROTASIO, 2008, p.14). Novamente isso se explica usando o exemplo do cristão: quando se peca ilude-se de que se é um cristão, mas vive-se sobre o constrangimento de ser um cristão que peca (que não é ser um verdadeiro cristão).

Brandt (1963) ressalta que o desespero não é o desespero sobre algo, sobre alguma coisa fora de mim, mas sim o desespero do "eu". Seu exemplo clarifica essa afirmação: uma mulher que perde o seu amado não se desespera por tê-lo perdido; desespera sobre si mesma, pois seu "eu" ainda quer viver com um relacionamento, e se constrange em "não ser o eu que se ilude ser" (PROTASIO, 2008, p.14).

Para Kierkegaard (2006 [1849]) há o desespero de não querer ser si mesmo e o desespero de querer ser si mesmo. Protasio (2008) exemplifica o desespero de não querer ser si mesmo com momentos na clínica em que ocorre uma tendência de culpar os outros pelas suas não-realizações, não percebendo o eu como um agente de realização. Brandt (1963) afirma que não se entende o seu "eu", e a necessidade de desenvolvê-lo, de vivê-lo como indivíduo e com uma verdade subjetiva. Define ainda o desespero de querer ser si mesmo como uma pessoa que quer ser o seu "eu" atual e não pensa em melhorar suas imperfeições. Aceita-se o "eu" que se tem e não se deseja melhorá-lo. O exemplo recém-demonstrado também pode ser 
aplicado aqui, demonstrando a dialética kierkegaardiana. O que se desdobra disso é a conclusão que o desespero é uma condição universal.

\section{Considerações Finais}

Para Rollo May (1977), Kierkegaard aponta para uma diferença entre - ser "saudável" - que concretizaria sua liberdade - e o ser "neurótico" - que sacrificaria sua liberdade. Ou seja, por mais angustiante que seja ter de vivenciar a liberdade, ela é em si saudável, pois gera movimento. Mas a pessoa que se fecha em apenas uma condição, essa sim é a "neurótica", pois quando enfrenta um problema não consegue modificar seu pensamento e realizar uma escolha que a beneficie.

A angústia - para muitas perspectivas clínicas - surge como "objeto" por excelência, o que traz inúmeras possibilidades do sujeito dessa clínica, no enfrentamento de seus conflitos cotidianos. A isto se aplica o que escreve Rollo May (1977): "a presença da ansiedade significa que um conflito está em curso e, na medida em que isso é verdade, é possível uma solução construtiva" (p. 58). No entanto, a possibilidade não é somente construtiva, pois outra possibilidade pode envolver também aspectos destrutivos. Disso decorre também que a pessoa criativa é aquela na qual a angústia mais está potencialmente presente.

Cabe ao psicólogo, como médico da "alma", auxiliá-lo a trilhar o caminho da descoberta do "eu", o caminho necessário para poder se tornar um indivíduo. Compreender-se a si mesmo não é tarefa fácil. Reale e Antiseri (1990), falando da teoria kierkegaardiana afirmam que é bem mais fácil se conhecer uma ou outra ciência do que compreender-se a si mesmo. Conhecer as coisas objetivamente é simples e direto. Kierkegaard nos auxiliou no conhecimento de nós mesmos, a compreender questões universais como a angústia e o desespero, mas também como elas estão atreladas à individualidade de cada um. Kierkegaard nos auxiliou a compreender que:

\footnotetext{
A existência sadia dá-se quando o eu, sabendo-se paradoxal, "decide" por si próprio, perante si, ao mundo e a Deus. Este eu sai da ilusão pelo movimento de transparecer-se a si mesmo. Realiza-se como indivíduo, contrapondo-se ao "todo mundo", à multidão, singularizando-se, criando a si próprio (PROTASIO, 2008, p.21).
}

O psicólogo, como um sujeito que lida com a compreensão da subjetividade humana, no contato com o outro sujeito, pode ser um suporte ou auxílio ao desenvolvimento ou crescimento daquele que o procura. Nisto, a clínica - dentre todas as suas possibilidades - pode 
ainda ter um caráter pragmático que envolve crescimento, autoconsciência e redefinição de relações com o mundo.

\section{Referências}

ABBAGNANO, N. Diccionario de Filosofia. México: Fondo de Cultura Econômica, 1992.

ARANGUREN, J. L. L. Introduccion. In: Kierkegaard, S. A. EI Concepto de Angustia. Madrid: Espasa-Calpe S. A., 1982.

BEAUFRET, J. Introdução às Filosofias da Existência: de Kierkegaard a Heidegger. São Paulo: Duas Cidades, 1976 [1971].

BRANDT, F. Soren Kierkegaard - His Life - His Works. Copenhague: Danske Selskab.

BUBER, M. Do Diálogo e do Dialógico. São Paulo: Perspectiva, 1982.

FARAGO, F. Compreender Kierkegaard. Rio de Janeiro: Vozes, 2006.

FEIJOO, A. M. C. de. Os Fundamentos da Clínica Psicológica na Filosofia de Soren Kierkegaard. Revista da Abordagem Gestáltica, Goiânia, v. 13, n. 1, p. 111-124, 2007.

FEIJOO, A. M. C. de. A filosofia da existência e os fundamentos da clínica psicológica. Estudos e Pesquisas em Psicologia [online], Rio de Janeiro, v. 8, n. 2, p. 309-318, 2008.

FEIJOO, A. M. C. de; PROTASIO, M. M. O Resgate do Caráter Estético da Existência na Filosofia de Kierkegaard. Revista Filosofia Capital, Brasília, v. 6, p. 11-22, 2011.

HALE, G. A. Kierkegaard Who? The Problem for Posterity. In: Kierkegaard and the Ends of Language. Minneapolis: University of Minnesota Press, 2002, p. 1-36.

HANNAY A.; MARINO, G. D. Introduction. In: HANNAY A.; MARINO, G. D. (Orgs.). Cambridge Companion to Kierkegaard. Cambridge: Cambridge University Press, 2006.

HOLANDA, A. F. Diálogo e Psicoterapia. Correlações entre Carl Rogers e Martin Buber. São Paulo: Lemos Editorial, 1998.

JOLIVET, R. El Existencialismo de Kierkegaard. Buenos Aires: Espasa-Calpe Argentina S. A., 1952.

J OLIVET, R. As Doutrinas Existencialistas, Porto: Livraria Tavares Martins, 1961.

JOLIVET, R. Dicionário de Obras Filosóficas. São Paulo: Martins Fontes, 2000.

KARWOWSKI, S. L. Gestalt-Terapia e Fenomenologia. Considerações sobre o Método Fenomenológico em Gestalt-Terapia. Campinas: Editora Livro Pleno, 2005.

KIERKEGAARD, S. O Conceito de Angústia. São Paulo: Hemus, 1968 [ 1844]. 
KIERKEGAARD, S. Ponto de vista explicativo de minha obra como escritor. Lisboa: Edições 70, 2002.

KIERKEGAARD, S. O Desespero Humano. São Paulo: Martin Claret, 2006 [1849].

KIERKEGAARD, S. Temor e Tremor. São Paulo: Livraria Exposição do Livro, s/d.

MARINO, G. D. Anxiety in The Concept of Anxiety. In: HANNAY, A.; MARINO, G. D. (Orgs.). Cambridge Companion to Kierkegaard. Cambridge: Cambridge University Press, 2006.

MAY, R. "Orígenes y Significado del Movimiento Existencial en Psicología", In: MAY, R.; ANGEL, E.; ELLENBERGER, H. F. (Eds.). Existencia. Madrid: Editorial Gredos S. A., 1967.

MESNARD, P. Kierkegaard. Lisboa: Edições 70, 1986 [1953].

MORA, J. F. Dicionário de Filosofia. 3 Vols. São Paulo: Loyola, 2001.

OSTENFELD, I. Søren Kierkegaard's Psychology. Ontario: Wilfrid Laurier University Press, 1978.

PENNA, A. G. (1985). Sobre os Fundamentos Históricos e Conceptuais da Psicologia Existencial: Acerca das Contribuições de Kierkegaard, Arquivos Brasileiros de Psicologia, Rio de Janeiro, v. 37, n. 2, p. 8-15.

PERES, M. A.; HOLANDA, A. F. de. A Noção de Angústia na Prática Clínica: Aproximações entre o Pensamento de Kierkegaard e a Gestalt-terapia. Estudos e Pesquisas em Psicologia [Online], Rio de Janeiro, v. 3, n. 2, p. 97-117, 2003. Disponível em: <http://www.revispsi.uerj. br/v3n2/artigos/artigo6V3N2.html>.

Acesso em: 11 jan. 2009.

PROTASIO, M. M. Contribuições Kierkegaardianas para a compreensão do adoecimento psíquico. In: FEIJOO, A. M. C. de (Org.). Interpretações Fenomenológico-Existenciais para o Sofrimento Psíquico na Atualidade. Rio de Janeiro: Edições IFEN, 2008, p. 1-34.

REALE, G.; ANTISERI, D. História da filosofia: Do Romantismo até nossos dias. $2^{\circ}$ ed. São Paulo: Paulus, 1990.

REALE, G.; ANTISERI, D. História da filosofia: Do Romantismo ao Empirocriticismo. São Paulo: Paulus, 2005.

RIBEIRO, J. P. Gestalt-Terapia. Refazendo um Caminho. São Paulo: Summus, 1985.

PONTE, C. R. S. Sobre os Conceitos de Indivíduo em Sören Kierkegaard e de Pessoa em Carl Rogers: Semelhanças e Diferenças. 2010. 118f Dissertação (Mestrado em Psicologia) Universidade Federal do Ceará, Fortaleza.

ROGERS, C. R. On Becoming a Person. Boston: Houghton Mifflin Co., 1961.

STRATHERN, P. Kierkegaard em 90 Minutos. Rio de Janeiro: Jorge Zahar Editor, 1999. 
WAHL, J. A Short Story of Existentialism. New York: The Philosophical Lybrary, 1949 [1947].

YONTEF, G. Processo, Diálogo e Awareness: Ensaios em GestaltTerapia. São Paulo: Summus, 1998.

\section{Endereço para correspondência Marcos Ricardo J anzen}

Laboratório de Fenomenologia Experimental e Cognição, Universidade Federal do Rio Grande do Sul, Instituto de Psicologia. Rua Ramiro Barcelos, 2600, sala 123, Porto Alegre, RS, Brasil

Endereço eletrônico: marcosjanzen@gmail.com

\section{Adriano Holanda}

Departamento de Psicologia, Universidade Federal do Paraná, Praça Santos Andrade, 50 - Sala 215, Ala Alfredo Buffren, Curitiba, PR, Brasil

Endereço eletrônico: aholanda@ufpr.br

Recebido em: 17/03/2011

Reformulado em: 16/05/2011

Aceito para publicação em: 17/05/2011

Acompanhamento do processo editorial: Ana Maria Lopes Calvo de Feijoo

\section{Notas}

* Mestrando em psicologia pela Universidade Federal do Rio Grande do Sul.

** Professor Doutor Adjunto da Universidade Federal do Paraná.

${ }^{1}$ Platão buscava uma verdade essencial que deveria ser a mesma em todas as pessoas. Como seu mestre Sócrates, Platão busca descobrir as verdades essenciais das coisas. Era uma busca racional, que Kierkegaard provavelmente consideraria como uma abstração, visto que estaria desvencilhada da vivência e verdade do Indivíduo, aspectos que serão explorados mais à frente.

${ }^{2}$ Pois, opostamente aos animais onde a espécie como um todo é mais importante que um animal em separado, para Kierkegaard o indivíduo vale mais que a espécie, pois é ao mesmo tempo um indivíduo singular, como também toda a humanidade (generalização).

${ }^{3}$ Que corresponderia, em dinamarquês, ao nosso "J oão".

${ }^{4} \mathrm{Ou}$ Either-Or na versão traduzida para o inglês. Em português, costuma ser traduzido por Ou...Ou.

${ }^{5}$ Nesse livro Kierkegaard comenta que não é a morte física que traz medo ao cristão ( visto que sua vida continuará na eternidade), mas sim a morte espiritual, àquilo que Kierkegaard caracteriza como o desespero. 